\title{
elyra
}

\section{Poesia, performance e feminismo: \\ (re)visões da contemporaneidade}

\section{Tatiana Pequeno \\ Universidade Federal Fluminense}

Resumo: O texto deseja inventariar e discutir as relações entre poesia, performance e feminismos a partir (inclusive) de uma (auto) reflexão sobre a sombra da tradição do silêncio na produção de arte por mulheres do século XX até o presente.

Palavras-chave: arte, performance, literatura

Abstract: The text intends to inventory and discuss the relations between poetry, performance and feminisms from (including) a (self) reflection on the shadow of the tradition of silence in the production of art by women from the twentieth century to the present.

Keywords: art, performance, literature

(...) a solidão da artista feminina, seus sentimentos de alienação em relação aos predecessores masculinos junto com sua necessidade de precursora $e$ sucessora fraterna, sua percepção premente da necessidade de um público feminino junto com seu medo do antagonismo dos leitores masculinos, sua timidez culturalmente condicionada em relação à autodramatização, seu temor da autoridade patriarcal da arte, sua ansiedade e relação à impropriedade da invenção feminina - todos esses fenômenos da 
"inferiorização" marcam a luta da mulher escritora por autodefinição artística e diferencia seus esforços de autocriação daqueles de seus pares masculinos.

Sandra M. Gilbert \& Susan Gulbar (com grifos nossos)

\section{I - Perspectiva}

Em entrevista a um programa de televisão (2013) do estado do Paraná (no Brasil), a artista e professora da Universidade Estadual de Londrina, Fernanda Magalhães, discorre como seu trabalho sobre corpos gordos foi tomando, cada vez mais, o lugar da performance. Implicada em sua própria obra, inicialmente de colagens fotográficas, e tomando um espaço reivindicatório cada vez mais assumido como uma narrativa pública, Fernanda Magalhães sugere que sua obra seja compreendida também como vazante contra o silenciamento e o apagamento a que socialmente era submetida. Entendendo que tal submissão também era admitida em função de sua autorização à docilidade de seu corpo, a artista constrói a própria demanda por uma reivindicação, que pode ser pautada pelas interações entre arte e ativismo, na medida em que evoca o desejo de tensionar as representações vigentes e quase sempre midiáticas do corpo feminino. Tiina Rosemberg, em seu artigo "On feminist activist aesthetics", observa:

Performance is about presenting and enacting, but it is not necessarily tied to traditional theatrical acting. Performance is a hybrid, where no rules limit what can be mixed, or how. Thus, it is a tumbling place for encounters between political activism, autobiography, popular culture, ritual body art, and the "ordinary" commonplace. One significant trait is the multiple voices, the lack of hierarchic components in the performance. Instead, performance strives to attain simultaneousness, a concurrent effect that the audience is free to structure and evaluate for itself (Rosemberg 2009: 9)

Com efeito, destacamos inicialmente aquilo que move nosso interesse na composição do presente artigo: a relação entre o desvelamento do silêncio e o caminho para a performance enquanto possibilidade de encontros entre ativismo político, autobiografia, 
cultura popular e um certo ritual de body art, como assinala o texto. Neste sentido, o excerto dialoga com a proposta de Fernanda Magalhães no texto de abertura de suas ações envolvendo mulheres gordas: "Expor seus corpos, deixar seus rastros, uma intenção política de se mostrar e ocupar seu espaço no mundo" (Magalhães 2010: 213) e pode, a partir da ideia do rastro, ensejar uma relação com a poesia contemporânea produzida por mulheres.

Recentemente, na última edição da Festa Literária de Paraty, idealizada por Joselia Aguiar, a escritora e tradutora Adelaide Ivánova participou da mostra "Fruto estranho", na qual apresentou a leitura de um poema seu por doze minutos e trinta e cinco segundos (Ivánova 2017), caminhando para um lado e para o outro enquanto segurava um caderno de capa vermelha entre as mãos. O poema de Adelaide, mesclado pelo peso e a densidade das imagens narradas - problematizadas a partir de Susan Sontag - e a figura diáfana da artista, com seu tom de voz ora puramente descritivo, inconformado com o material que lia, interagem assim com a sua (talvez principal) plataforma de acontecimentos políticos: o corpo. A performance de Adelaide, desse modo, a conduz ao espaço central do palco e a faz deambular inquieta, onde também parece lutar contra o silêncio e o emudecimento/ amortecimento das imagens que evoca. É o trânsito de seu corpo que parece lutar contra a anestesia do horror narrado pela exploração das imagens de mulheres violadas, numa atuação que parece - como o próprio poema considera a partir de Sontag - que "imagens do repugnante também podem seduzir" já que, conforme a continuação da citação, "Nós também temos um apetite por cenas de degradação, dor e mutilação" (Sontag 2003: 81). A performance da poeta expõe, assim, uma narrativa violenta do horror vivenciado pelas mulheres no Brasil, colocando em questão inclusive a própria natureza misógina dos acontecimentos políticos que levaram ao impeachment da ex-presidenta Dilma Rousseff que na seleção de imagens curadas por Adelaide é atravessada pela marca da violação ou da humilhação de seu corpo: seja em foto em que aparece atravessada por uma espada, seja na apropriação imagética feita pela imprensa nacional de quando a chefe de estado torcia vibrantemente em jogo de futebol para o uso de uma foto em tom de denuncismo a respeito do humor da presidenta, seja no uso de adesivos onde aparece de pernas abertas para ser penetrada pela bomba de combustível. Os adesivos foram usados durante a extensa campanha para sua desmoralização. 
Com efeito, a poeta radicada na Alemanha parece performar seu poema ciente de que contar o horror talvez convoque um conflito entre o testemunho e a manutenção do silêncio, coincidindo com o que Fernanda Magalhães já aventara em seu texto. É neste sentido também que a produção artística de mulheres permite a discussão de um atravessamento que sugere a dúvida entre falar e calar, entre performar e silenciar. Ciente, portanto, da tradição na qual está inserida, a poeta assume a performance e lembra que poemas e leis não mudam as histórias de horror das mulheres, pontuando: "Mas meu Deus, de que adiantaria meu silêncio?/ De quem estaria meu silêncio a serviço?" (Ivánova 2017). Hélène Cixous, em "La venue a l'écriture", também atravessa este problema anunciado na produção artística de mulheres:

Et à la femme. il n'est même pas permis d'espérer avoir tout ce qu'un être humain peut avoir. Il y a tant de frontières, et tant de murailles, et à l'intérieur des murailles, d'autres murailles. Bastions, dans lesquels, un matin, je me réveille condamnée. Villes où je suis isolée, quarantaines, cages, maisons de "santé", si souvent j'y suis allé, mes tombes, mes mitards corporels, la terre pleine de lieux de réclusion pour moi. Le corps au cachot, l'esprit au silence. Périodes de prison : quand j' y suis, la peine est vraiment d'une longueur et d'une nature imprévisibles. (Cixous 1986: 12)

Como é ainda recente a referida vinda ou chegada da escrita para as mulheres, a linguagem opera também através de influxos, dificuldades nos processos de manutenção do fôlego ou da pausa, ilustrando, em alguns casos, a precariedade da intimidade com o fazer artístico. A mulher hesita e seus trabalhos evocam esse processo de hesitação, o que também pode ser admitido como tradução metalinguística de seu trabalho de composição ou performance.

\section{II - Vivência}

A moça que me inspira, vista tão pouco e de tão longe é meu colchão, lençol, travesseiro o que é de mim mais perto onde me deito, foi feita dessa matéria de bonecas 
pobres (nem louça inglesa nem corda) precisa da menina que a aquece, beija e roda

Simone Brantes

No Rio de Janeiro, diversos eventos de performances poéticas têm ocorrido, sobretudo os que dão destaque às questões de gênero. Neste sentido, valeria à pena selecionar dois eventos dos quais participei: um como curadora e outro como mediadora.

Em outubro de 2017, dentro do evento de arte A MESA, espaço-laboratório que pretende discutir e organizar a produção de trabalhos que deem a ver múltiplas linguagens artísticas, localizado no Morro da Conceição, região portuária da cidade do Rio de Janeiro, realizou-se o Encontro de Poetas - com curadoria minha - cuja temática era a de pensar a relação entre a cidade e a ruína. O evento, apesar de não ter privilegiado um recorte em que o feminino prefigurasse, contou com oito poetas mulheres participantes: Bruna Mitrano, Stephanie Borges, Letícia Feres, Simone Brantes (ganhadora do Prêmio Jabuti de Poesia 2017), Jaqueline Ferreira, Yassu Noguchi, Rita Isadora Pessoa e Luanna Belmont. Além das mulheres, houve a participação de Leonardo Marona e da performance musical de Alê Fenerich.

A performance das poetas esteve conectada à uma relação de tensão com a dinâmica da cena, dado o espaço em que ocorrem os eventos d'A Mesa: no meio de uma praça pública a céu aberto, com toda sorte de ruídos que entrecortam as apresentações. Assim, é importante observar que as interseções entre poesia, performance e feminismo estão sendo tecidas no campo das vivências e na costura de um caderno de memórias que a própria efemeridade dessa linguagem artística - a própria performance - tende a se dissipar. Não obstante, como observa Regina Melim em (2008: 46), há cada vez mais esforços, na contemporaneidade, para que a ação permaneça, tornando-se acervo através de processos de documentação: fotografias, vídeos, roteiros, desenhos. Neste sentido, as apresentações das poetas no Morro da Conceição contou com variadas possibilidades de registros. O mais importante, dessa experiência, foi a leitura que cada poeta fez de seu poema de sua autoria, como se essa construção de uma espécie de mapa afetivo da cidade ruída pudesse aplacar 
ou interromper, ainda que fragilmente, as fissuras provocadas no território e nas relações sociais.

Um outro exemplo com que gostaria de ilustrar as relações já propostas no título de meu texto foi a edição Queridas poetas lésbicas, do grupo Mulheres que escrevem, coletivo encabeçado por Taís Bravo, Natasha R. Silva e Estela Rosa. Realizado na Blooks Livraria de Botafogo (RJ), o evento contou com a participação das escritoras Angélica Freitas, Dara Bandeira e Maria Isabel lorio, sob minha mediação. A ação durou quase quatro horas de uma ininterrupta conversa e ação de leitura. Cinco perguntas foram preparadas antecipadamente para que cada autora pudesse relacionar questões relativas a feminismo, lesbiandade, espaço editorial, micropolítica e poesia. Com um público bastante numeroso e muito interessado, a performance acabou por denunciar a carência de uma representação que leve em consideração não apenas as questões de gênero, mas também formas de colocar em pauta as experiências de sexualidade da mulher, evitando o tradicional silenciamento de suas experiências, como lembra Helena Reckitt, importante curadora canadense, no prefácio de Art and Feminism (2012: 13):

Although the prospects for women artists have improved to some extent during the period surveyed, feminist artists still face numerous prejudices and obstacles. Their work is generally considered to be less marketable and collectable than men's. All too many of the major artists in this book are not adequately represented commercially and are unable to make a living from their art. Female artists are frequently expected to perform "attractive" and "youthful" personae, in a reductive equation of hot artists with hot art. (...) This suggests that the arts still needs feminism, perhaps more than certain women artists suspect.

Assim, se para boa parte da crítica literária (mais do que da crítica de arte), a obra não possui qualquer traço ou marca da sexualidade ou gênero, a produção local, brasileira, das mulheres aqui mencionadas, vai de encontro a uma tradição que ignora ou encobre a violência simbólica sofrida pela manutenção dos privilégios editoriais e críticos de gênero. Fique registrado que pelo menos a autoria, nestes casos, foi devidamente marcada e assinada, como que revigorando uma outra tradição, a das narrativas feministas que insistem em lembrar: o pessoal é político. 


\section{Bibliografia}

Brantes, Simone (2016), Quase todas as noites, Rio de janeiro, 7letras.

Cixous, Hélène, Entre l'écriture, Paris, Des femmes, 1986.

Ivánova, Adelaide (2017), "Fruto estranho", performance realizada em 29/07/17, na Flip,

Parati (RJ), <https://www.youtube.com/watch?v=sameT-la618> (último acesso em 12/12/17).

Magalhães, Fernanda, Corpo-reconstrução. Ação ritual performance, Londrina, Travessa dos Editores, 2010.

-- (2013), entrevista em gente.com, tv e-paraná <https://www.youtube.com/ watch?v=Kzz3oSBh-eE $>$ (último acesso em 12/1217).

Melim, Regina, Performance nas artes visuais, Rio de Janeiro, Zahar, 2008.

Reckitt, Helena \& Phelan, Peggy (2012), Art \& Feminism, New York, Phaidon.

Rosenberg, Tiina (2009), "On feminist activist aesthetics", <http://www.tandfonline.com/ doi/pdf/10.3402/jac.v1i0.4619> (último acesso em 30/10/17).

Showater, Elaine (1994), "A crítica feminista no território selvagem", trad. de Deise Amaral, in Heloisa Buarque de Holanda (org.), Tendências e impasses. O feminismo como crítica de cultura, Rio de Janeiro, Rocco.

Sontag, Susan, Diante da dor dos outros, São Paulo, Companhia das Letras, 2003.

Tatiana Pequeno é professora do Instituto de Letras da Universidade Federal Fluminense (Niterói/ Brasil), onde coordena o grupo de pesquisa "Corpo, gênero e sexualidades nas literaturas de língua portuguesa". Também assina como poeta e cronista, tendo publicado dois livros de poesia: réplica das urtigas, 2009 e Aceno, 2014. 